\title{
Human endothelial cells bioactivate organic nitrates to nitric oxide: implications for the reinforcement of endothelial defence mechanisms
}

\author{
M. FEELISCH, F. BRANDS \& M. KELM* Department of Nitric Oxide Research, Schwarz Pharma AG, \\ Monheim and *Department of Cardiology, Heinrich-Heine University, Düsseldorf, Germany
}

Received 18 May 1995; accepted 4 July 1995

\begin{abstract}
Although in therapeutic use for more than a century, the mode of cellular action of organic nitrates remains incompletely understood. Despite ample experimental evidence from animal studies to show that nitrates are metabolized to NO in the vascular smooth muscle, direct demonstration of such an activity in human vascular cells is still lacking. Moreover, the role of the endothelium in modulating the pharmacodynamic action of nitrates is far from clear. We therefore aimed to investigate whether or not human endothelial cells are capable of bioactivating these drugs to $\mathrm{NO}$ and whether the amounts generated are sufficient to elicit any biological effects. Using cultured human umbilical vein endothelial cells (HUVECs) as an established model system a combination of three different methods was used to address this issue: (1) quantification of NO formation upon endothelial nitrate metabolism using the oxyhaemoglobin technique; (2) evaluation of the second messenger response using radioimmunoassay for CGMP; and (3) assessment of mechanism and extent of potentiation of the anti-aggregatory effect of nitrates in the presence of endothelial cells as a relevant bioassay. We now show that superfusion of cultured human endothelial cells on microcarrier beads with either glyceryl trinitrate (GTN) or isosorbide dinitrate (ISDN; both at $0 \cdot 1-100 \mu \mathrm{mol} \mathrm{L}^{-1}$ ) results in a concentration-dependent formation of NO. NO generation from isosorbide 5-mononitrate (IS-5-N) was below the detection limit. The amounts of NO produced (maximally $2.97 \pm 0.98$ pmoles NO min $^{-1} \times \mathrm{mg}$ protein with $100 \mu \mathrm{mol} \mathrm{L}^{-1} \mathrm{GTN} ; n=8$ ) were similar to those elicited upon challenge of the cells with $100 \mathrm{~nm}$ bradykinin. NO formation from either organic nitrate was accompanied, in a concentration-dependent and methylene blue-inhibitable manner, by stimulation of endothelial soluble guanylyl cyclase with consequent increases in the intracellular level of cGMP (maximally 32-fold over basal levels with ISDN), a significant portion of which was released into the extracellular space. Upon continuous
\end{abstract}

Correspondence: Dr M. Feelisch. Department of Nitric Oxide Research, Schwarz Pharma AG, Alfred Nobel Str. 10, D-40789 Monheim, Germany.
30 min superfusion or repeated application of high concentrations of GTN $\left(100 \mu \mathrm{mol} \mathrm{L}^{-1}\right)$ nitrate bioactivation to NO was subject to partial tachyphylaxis. Co-incubation of washed human platelets with HUVECs potentiated the anti-aggregatory action of nitrates in a cell number dependent and oxyhaemoglobin-sensitive manner and this effect, too, was accompanied by increases in intraplatelet cGMP levels. The potentiating effect was largely inhibited after blockade of sulfhydryl groups by pre-incubation of HUVECs with $\mathrm{N}$-ethylmaleimide and completely abrogated after pretreatment of cells with the tissue fixative glutaraldehyde. These results demonstrate that human endothelial cells are capable of bioactivating organic nitrates to NO by an enzymatic, apparently thiol-sensitive pathway, in quantities sufficient to influence endothelial and platelet function. Besides the well known vasorelaxant action of organic nitrates, which is mainly due to their metabolism in the smooth muscle compartment, these drugs may therefore be endowed with a hitherto underestimated potential to directly influence endothelial functions via the $\mathrm{NO} /$ cGMP pathway. Through specific bioactivation in the endothelium itself organic nitrates can thus mimic and reinforce protective functions normally served by a functional endothelium such as the modulation of blood cell/vessel wall interactions and inhibition of cell proliferation.

Keywords. Cyclic GMP, endothelium, nitric oxide, organic nitrates, platelet aggregation.

\section{Introduction}

More than 120 years after publication of the first reports on the usefulness of organic nitrates for the relief from acute attacks of angina pectoris [1] these drugs, along with betablockers and calcium channel antagonists, continue to represent the mainstay of anti-anginal therapy. More recently, organic nitrates experienced a remarkable revival with the finding that they have to be regarded as prodrugs acting via the release of nitric oxide (NO), a discovery which coincided with the demonstration that the 
endothelium-derived relaxing factor (EDRF) is chemically identical with NO $[2,3]$. Both therapeutically generated and endogenously formed NO thus share a common pathway, i.e. stimulation of the target enzyme soluble guanylyl cyclase (sGC) with subsequent elevation of intracellular cyclic guanosine monophosphate (cGMP) levels. The growing knowledge regarding the diverse bioregulatory roles of NO in cell function and cell communication as well as its involvement in host defence mechanisms renewed basic scientific interest in nitrate compounds and triggered investigations on other biological actions unrelated to their well known mechanism of vasorelaxation. Despite earlier recognition that the endothelium represents an important cellular layer controlling vascular tone, cell proliferation as well as blood cell adhesion and activation, its involvement in the metabolism of organic nitrates has attracted surprisingly little attention [4-6]. Even more surprising is that the proposed mechanism of action of organic nitrates at the cellular level, i.e. their biotransformation to NO, has not been demonstrated yet in human vascular cells. Functional results on the contribution of the endothelium for the vasorelaxant effect of organic nitrates have revealed conflicting results: whereas in most investigations an increase in potency of GTN after removal of the endothelium is seen ([7] and ref. cited therein), at least one other report described a reduction of potency after endothelial denudation [8]. Thus, the role of the endothelium in modulating the pharmacodynamic action of organic nitrates is far from clear and warrants further investigation. The aim of the present study, therefore, was to investigate whether or not human endothelial cells in culture are capable of metabolically activating organic nitrates to NO and, if so, whether the amounts of NO formed are sufficiently high as to modulate enclothelial and blood cell function via stimulation of sGC activity.

\section{Methods}

\section{Cell culture}

Human umbilical vein endothelial cells (HUVECs) were harvested enzymatically from umbilical cord within $12 \mathrm{~h}$ post-partum by a modification of the method originally described by Jaffe and co-workers [9]. Briefly, a teflon cannula (Intraflon 2, $16 \mathrm{G}$, Vygon, Ecouen. France) was inserted into the vein and tightened in order to rinse the blood vessel with sterile phosphate-buffered saline (PBS) for removal of blood. After incubation with $0.05 \%$ dispase (grade II, $2.4 \mathrm{U} \mathrm{mL}^{-1}$; Boehringer Mannheim, Germany) for $30 \mathrm{~min}$ at $37^{\circ} \mathrm{C}$ detached cells were collected under sterile conditions in culture medium and centrifuged at $200 \mathrm{~g}$ for $5 \mathrm{~min}$. The pellet was resuspended in culture medium and seeded onto plastic dishes (Primaria, Falcon, Heidelberg, Germany) previously coated with $0.025 \mathrm{mg} \mathrm{mL}^{-1}$ human fibronectin (Bio- chrom, Berlin, Germany). Four to five hours after seeding the medium was exchanged for the first time after gentle rinsing of the cells with fresh culture medium. Cells were cultured in M199 medium with Earle's salts (Boehringer Mannheim) which was supplemented with $10 \%(\mathrm{v} / \mathrm{v})$ fetal calf serum (Gibco BRL, Eggenstein, Germany) and 10\% human serum (Sigma, Deisenhofen, Germany), $40 \mu \mathrm{g} \mathrm{mL}^{-1}$ endothelial cell growth factor (ECGF; from bovine brain. Boehringer Mannheim), and $50 \mu \mathrm{g} \mathrm{mL}^{-1}$ heparin (Sigma). Within the first 5 days of culture the medium was additionally supplemented with gentamicin $\left(50 \mu \mathrm{g} \mathrm{mL}^{-1}\right)$, penicillin $\mathrm{G}\left(100 \mathrm{U} \mathrm{mL}^{-1}\right)$, streptomycin $\left(100 \mu \mathrm{g} \mathrm{mL}^{-1}\right)$, amphotericin $\mathrm{B}\left(5 \mu \mathrm{g} \mathrm{mL}^{-1}\right.$; all from Boehringer Mannheim) and ofloxacin ( $200 \mu \mathrm{g} \mathrm{mL}^{-1}$; Hoechst, Frankfurt/Main). The cells were incubated at $37^{\circ} \mathrm{C}$ in a humidified atmosphere of $95 \%$ air $/ 5 \% \mathrm{CO}_{2}$ and the medium was changed daily. Typically, after 4-5 days cells reached confluence and were passaged using trypsin/EDTA (Sigma) with a split ratio of $1: 2$. HUVECs of passage 2-4 were grown to confluence on fibronectin-coated plastic dishes and were characterized morphologically by their typical cobblestone-like growth pattern [9]. In addition, cells of each batch were routinely grown on glass coverslips and examined by immunofluorescence microscopy for the presence of factor VIII-related antigen using a monoclonal antibody against human von Willebrand factor (Boehringer Mannheim) [9] and for the uptake of acetylated low density lipoproteins (acLDL) using an antibody against acLDL coupled to $1,1^{\prime}$-dioctadecyl-1-3,3,3',3'-tetramethylindocarbocyanine perchlorate (Dil-ac-LDL, Paesel, Frankfurt/Main), [10]. Absence of possible contamination of cultured HUVECs with smooth muscle cells or fibroblasts was verified by counterstaining of cell nuclei with bisbenzimide (Hoechst dye 33258, Riedel de Haen, Frankfurt/Main) and with an antibody against smooth muscle $\alpha$-actin (Sigma). The purity of all HUVEC batches used for this investigation was $>98 \%$.

\section{Nitric oxide measurement}

For the measurement of NO, HUVECs of passage 24 were grown to confluence on fibronectin-coated microcarrier beads (Biosilon, $160-300 \mu \mathrm{mol} \mathrm{L}^{-1}$; Nunc, Wiesbaden; initial seeding density 5$6 \times 10^{6}$ cells $^{-1}$ carrier). One millilitre of cell-covered beads corresponded to $3.3 \pm 0.5 \mathrm{mg}$ endothelial protein $(n=8)$. Cells on plastic beads were placed in a water-jacketed chromatography column (C 10/10, Pharmacia, Freiburg, Germany) maintained at $37^{\circ} \mathrm{C}$ and superfused at $2.0 \mathrm{~mL} \mathrm{~min}^{-1}$ with HEPES-buffered Krebs Ringer solution ( $\mathrm{pH} 7 \cdot 4, \mathrm{pO}_{2} 150-160 \mathrm{mmHg}$, $37^{\circ} \mathrm{C}$ ) additionally supplemented with $4 \mu \mathrm{mol} \mathrm{L}^{-1}$ oxyhaemoglobin [5]. The column effluent was continuously passed through the flow-through cell of a dual-wavelength spectrophotometer (Shimadzu UV-3000) and the release of NO was quantified 


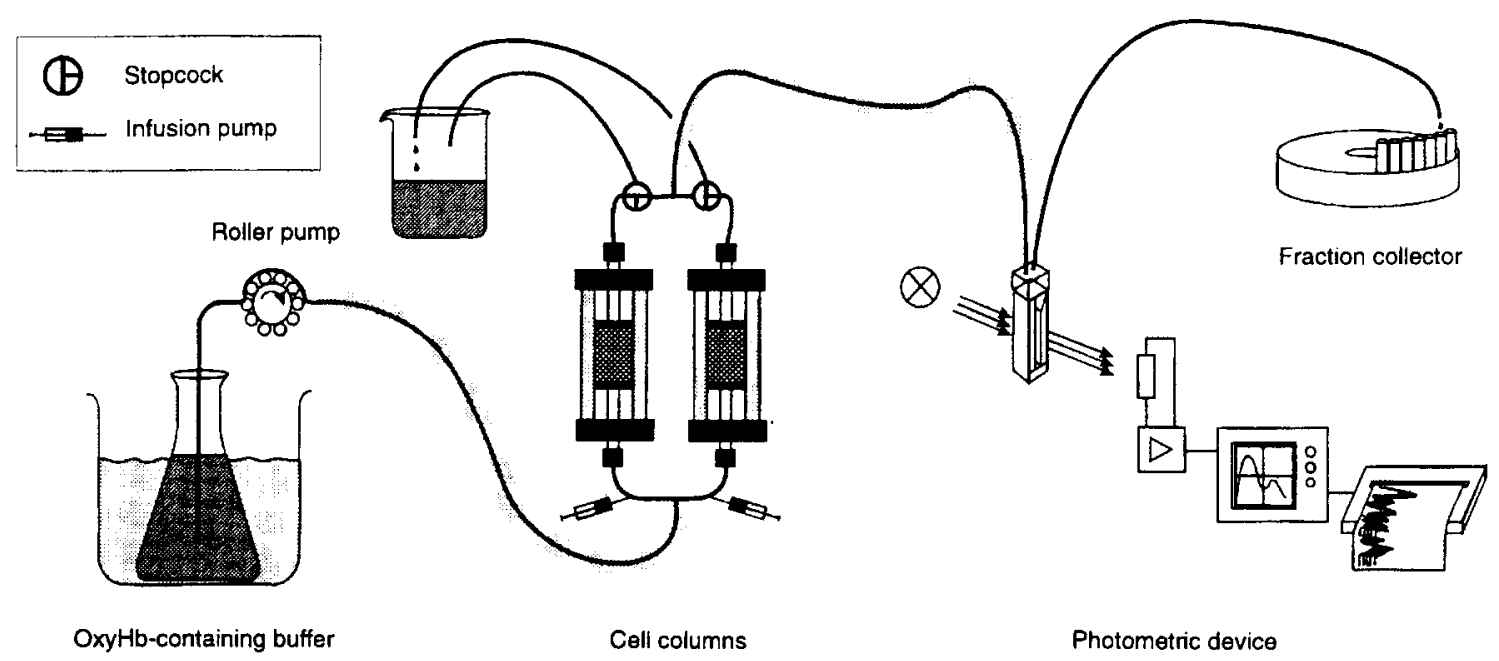

Figure 1. Set-up for the measurement of bioconversion of organic nitrates to NO using the oxyhaemoglobin technique. The perfusion flow of the oxyhaemoglobin-containing buffer solution can be switched, by means of two three-way stopcocks. between the chromatography column containing the cultured cells on microcarrier beads and a second column with naked beads corresponding to the same dead space for determination of basal release and spontaneous NO formation of drugs in the absence of cells.

continuously using the oxyhaemoglobin technique (for general set-up see Fig. 1). This highly sensitive method has been proven specific for NO and is based on the difference-spectrophotometric quantification of methemoglobin, which is formed as the co-oxidation product of the reaction between oxyhaemoglobin and NO in a $1: 1$ stoichiometric ratio $[11,12]$. Detection wavelengths were set at 401.5 and $411 \mathrm{~nm}$ with $1 \mathrm{~nm}$ slit width and a molar extinction coefficient of $48 \mathrm{mmol} \mathrm{L}^{-1} \mathrm{~cm}^{-1}$ was used for the calculation of $\mathrm{NO}$ concentration under the conditions of this study. Data for NO formation were expressed either as maximal rates of release or as total amounts of NO production, tahing into account peak height and area under the curve, respectively.

After $30 \mathrm{~min}$ of equilibration cells were stimulated repeatedly with either bradykinin $(100 \mathrm{~nm}, 1 \mathrm{~min})$ or the respective organic nitrates by means of constant infusion (10-45 $\mu \mathrm{L} \mathrm{min}^{-1}$ ) of stock solutions into the cell perfusate using a high precision infusion pump (Precidor, Infors AG, Basel, Switzerland). Aliquots of the column effluent were collected at consecutive $90 \mathrm{~s}$ intervals for determination of released cGMP or lactate dehydrogenase (LDH) activity. Integrity of the endothelial cell membrane after $3 \mathrm{~h}$ of saline perfusion was verified by scanning electron microscopy and by the absence of any detectable LDH activity in the column effluent (LDH-Monotest, Boehringer Mannheim; detection limit $0.005 \mathrm{U} \mathrm{mL}^{-1}$; total LDH activity of HUVECs $40.5 \pm 1.5 \mathrm{U} \mathrm{mL}^{-1}$ bead volume; $n=3$ ). Cell viability was checked routinely at the end of the experiment using the trypan blue exclusion test. The protein content of HUVECcovered microcarrier beads was determined according to Lowry et al. [13] using bovine serum albumin as a standard.

\section{Determination of cGMP}

The amounts of cGMP released into the column effluent were determined by radioimmunoassay after purification and preconcentration of $3 \mathrm{~mL}$ aliquots over reversed-phase columns (C18-Sep-Pak cartridges, Millipore), subsequent evaporation of the eluate to dryness and reconstitution of the residue in $0.05 \mathrm{mmol} \mathrm{L}^{-1}$ acetate buffer as described previously [14]. In a separate set of experiments HUVECs of passage 3-5 were grown to confiuence on plastic dishes (Primaria, Falcon; $30 \mathrm{~mm}$ ), rinsed twice with PBS $\left(37^{\circ} \mathrm{C}\right)$ to remove serum constituents of the culture medium and thereafter incubated with the non-selective phosphodiesterase inhibitor, 3-isobutyl-1-methylxanthine $\left(5 \times 10^{-4} \mathrm{~mol} \mathrm{~L}^{-1}\right)$ for $30 \mathrm{~min}$ to block intracellular cGMP degradation. After aspiration of the supernatant and rinsing with PBS cells were subsequently incubated with increasing concentrations of either GTN, ISDN, IS-5-N $\left(1 \times 10^{-5}-10^{-3} \mathrm{~mol} \mathrm{~L}^{-1}\right)$ or the vehicle, respectively, for $5 \mathrm{~min}$ at $37^{\circ} \mathrm{C}$. In some of these experiments cells were pretreated with $1 \mu \mathrm{mol} \mathrm{L}^{-1}$ methylene blue $5 \mathrm{~min}$ prior to incubation with the nitrates. The supernatant from this incubation step was collected for determination of that portion of cGMP which was released into the extracellular medium. The cells were subjected to two freeze-thaw cycles using liquid nitrogen and intracellularly formed cGMP was extracted with ethanol $(98 \% ; 2 \times 1 \mathrm{~mL})$. Cells were scraped off with a rubber policeman, the suspension was transferred quantitatively into Eppendorff tubes, sonicated for $10 \mathrm{~s}$, and centrifuged for $10 \mathrm{~min}$ at $4500 \mathrm{~g}$. cGMP content in the supernatant was quantified using a commercially available radioimmunoassay kit $(125 \mathrm{~J}$ cGMP scintillation proximity assay, Amersham. Braunschweig, Germany) following evaporation of 
the extract to dryness, reconstitution in assay buffer and acetylation of the sample with acetic anhydride [15]. The pellet was resuspended in $1 \mathrm{~N}$ sodium hydroxide and stored at $-20^{\circ} \mathrm{C}$ for later determination of protein content by the method of Lowry et al. [13].

Nitrate-induced stimulation of platelet soluble guanylate cyclase in the absence and presence of HUVECs was determined in the platelet lysate according to the same protocol as described for the HUVECs following snap-freezing of the platelet/ HUVEC co-incubate in liquid nitrogen at the end of each aggregation run. No attempt was made to separate platelets from endothelial cells as guanylate cyclase activity in the latter corresponded to less than $1 \%$ of that in platelets.

\section{Platelet aggregation}

Human blood was collected and washed platelets (WP; $1.8-2.2 \times 10^{8}$ platelets $\mathrm{mL}^{-1}$ ) were prepared essentially as described previously [16]. Platelet aggregation was monitored turbidometrically at $37^{\circ} \mathrm{C}$ under stirring $(1000 \mathrm{rpm})$ in a total volume of $500 \mu \mathrm{L}$ using an APACT dual channel aggregometer. Aggregation was initiated by addition of collagen $\left(0 \cdot 5-2 \mu \mathrm{g} \mathrm{mL}^{-1}\right.$; Hormon Chemie, Munich, Germany) after pre-incubation of platelets with either GTN, ISDN or IS-5-N for $5 \mathrm{~min}$ in Tyrode buffer, and the platelet response was monitored for a further $5 \mathrm{~min}$. The anti-aggregating effect of the nitrates was assessed by taking into account the extent of inhibition of the area under the aggregation curve as compared to the platelet response to collagen under control conditions. In the co-incubation experiments platelets were pre-incubated with the nitrates for $5 \mathrm{~min}$ in the presence of HUVECs before the addition of collagen. The endothelial cells used in these experiments were pretreated with $10 \mu \mathrm{mol} \mathrm{L}^{-1}$ acetylsalicylic acid and $100 \mu \mathrm{mol} \mathrm{L}^{-1}$ L-nitroarginine for $30 \mathrm{~min}$ in order to prevent formation of anti-aggregatory prostanoids and endogenous NO, respectively. In some experiments, co-incubations were carried out in the presence of oxyhaemoglobin $\left(10 \mu \mathrm{mol} \mathrm{L}^{-1}\right)$ for trapping of extracellularly released NO or with HUVECs, which had been exposed for $30 \mathrm{~min}$ to a maximally tolerable (cell viability $>97 \%$ after $1 \mathrm{~h}$ ) concentration of N-ethylmaleimide (NEM; $10 \mu \mathrm{mol} \mathrm{L}^{-1}$ ) prior to addition to the platelet suspension in order to block reactive sulfhydryl groups. In order to control for possible non-specific effects, additional co-incubation experiments were performed with HUVECs which had been pretreated with the tissue fixative glutaraldehyde $(0.5 \%$ in phosphate-buffered saline) followed by extensive washing.

\section{Materials}

Oxyhaemoglobin was prepared from crystallised human haemoglobin as described earlier [12] and was stored in aliquots at $-20^{\circ} \mathrm{C}$. GTN and isosorbide dinitrate (ISDN) were diluted from commercial aqueous formulations (Perlinganit ${ }^{\mathrm{k}}$ and Isoket ${ }^{\mathrm{R}}$, Schwarz Pharma, Germany) in saline. Isosorbide 5mononitrate (IS-5-N) was dissolved in saline from crystalline compound (Schwarz Pharma). Buffer salts were of analytical grade and purchased from Merck, Darmstadt. All other chemicals were of the highest purity available and were purchased from Sigma, Deisenkirchen, Germany, if not otherwise specified.

\section{Calculations and statistics}

Results are expressed as means \pm SEM of $n$ individual experiments. Determinations of cGMP levels and protein content were performed in duplicate. Differences between total NO formation in tachyphylaxis experiments were compared by analysis of variance (ANOVA for repeated measures, two-sided). Data on the inhibition of platelet aggregation by GTN in the presence of HUVECs were compared using Student's $t$-test with Bonferroni correction. $P$ values of $<0.05$ were considered to denote statistical significance.

\section{Results}

\section{Formation of $\mathrm{NO}$}

Superfusion of HUVECs with GTN $(0 \cdot 1-$ $100 \mu \mathrm{mol} \mathrm{L}^{-1}$ ) resulted in the concentration-dependent formation of NO. No spontaneous generation of NO was observed at any concentration of GTN in the absence of vascular cells (Fig. 2). NO release was instantaneous and revealed a biphasic profile at higher concentrations of GTN. Maximal rates of NO formation from GTN $\left(100 \mu \mathrm{mol} \mathrm{L}^{-1}\right)$ amounted to

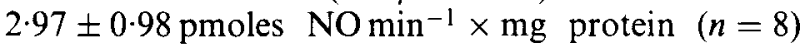
and were of the same order of magnitude as those achieved upon maximal stimulation of the cells with $100 \mathrm{~nm}$ bradykinin, which corresponds to an almost fourfold increase over basal NO release $(n=4$; data not shown). The net conversion of GTN to NO

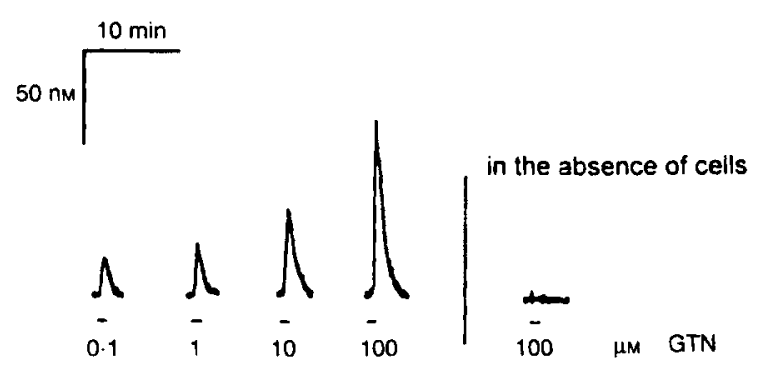

Figure 2. Representative tracings of NO formation from GTN $(0 \cdot 1$ $100 \mu \mathrm{mol} \mathrm{L} \mathrm{L}^{-1}, 1 \mathrm{~min}$ ) in the absence and presence of cultured human endothelial cells. Recordings are corrected for baseline drift due to autoxidation of oxyhaemoglobin and dilution-mediated effects due to volume changes elicited upon co-infusion of test compound or vehicle, respectively. 


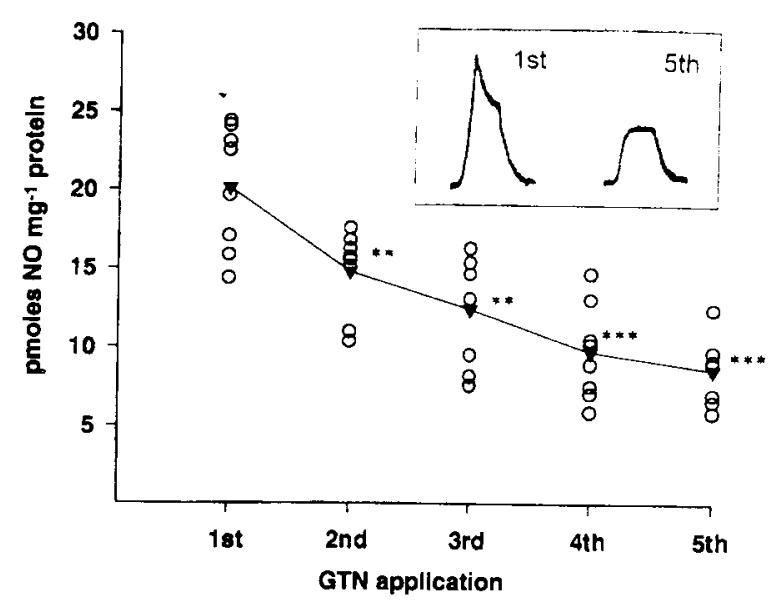

Figure 3. Decrease in total formation of NO upon repeated superfusion of human endothelial celis with GTN $\left(100 \mu \mathrm{mol} \mathrm{L}^{-1}, 3 \mathrm{~min}\right.$ : $n=8$ ). Inset: Representative tracing of NO response at the 1 st and 5th application of GTN. ${ }^{* *} P<0.01 ;{ }^{* * *} P<0.001$.

decreased with increasing concentration of the nitrate, corresponding to 0.1 and $0.003 \%$ per $\mathrm{mg}$ protein at 1 and $100 \mu \mathrm{mol} \mathrm{L}^{-1} \mathrm{GTN}$, respectively. When cells were repeatedly superfused with the highest concentration of GTN tested (100 $\mu \mathrm{M}$ for $3 \mathrm{~min}$; $15 \mathrm{~min}$ drug-free intervals) a progressive decrease of both, the maximal rate of NO formation and the total conversion to NO was observed (corresponding to a reduction by $79 \cdot 2$ and $56.3 \%$ for maximal and total NO formation comparing first and fifth stimulus; respectively) (Fig. 3). Upon continuous $30 \mathrm{~min}$ application of the same concentration of GTN the steady-state level of NO formation was reached after about 5 min corresponding to about $50 \%$ of peak NO formation rates with no indication for a further decrease over time (Fig. 4). Similarly, ISDN was metabolized to NO with maximal conversion rates approaching $25 \%$ of those obtained with GTN ( $n=3$; data not shown). In

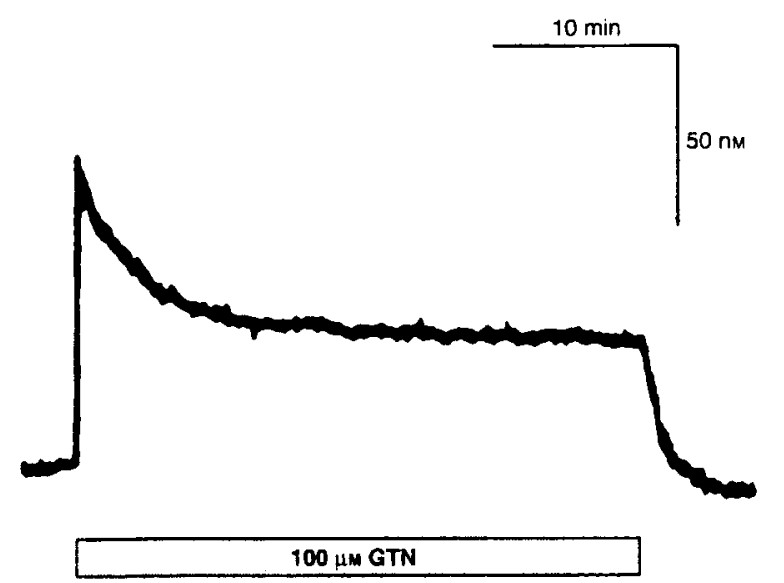

Figure 4. Profile of NO formation upon $30 \mathrm{~min}$ superfusion of human endothelial cells with $100 \mu \mathrm{mol} \mathrm{L}^{-1}$ GTN. Depicted tracing has been corrected for baseline drift and is representative of three similar experiments. contrast to GTN, NO release from ISDN was monophasic. Formation of NO from IS-5-N was below the detection limit of the assay $\left(<15\right.$ pmoles NO $\left.\mathrm{min}^{-1}\right)$, even at a concentration of $1 \mathrm{mmol} \mathrm{L}^{-1}(n=2)$.

\section{Stimulation of endothelial $s G C$}

The formation of NO from organic nitrates was accompanied by a concentration-dependent stimulation of endothelial sGC activity. As upon superfusion of HUVECs with GTN the release of cGMP into the perfusion medium was below the detection limit $\left(<0.25 \mathrm{fmoles} \mathrm{min}^{-1} \times \mathrm{mg}\right.$ protein $)$ in six out of eight experiments, a separate approach was used to estimate the extent of sGC activation by these drugs. For this purpose HUVECs grown on plastic dishes were challenged with either GTN, ISDN or IS-5-N and the amounts of both, intracellulary formed and extracellularly released cGMP were determined. Basal intraceliular cGMP levels in HUVECS amounted to $29 \cdot 5 \pm 5 \cdot 1 \mathrm{fmoles}$ cGMP $\mathrm{mg}^{-1}$ protein and increased, in a concentration-dependent and methylene blueinhibitable manner, upon short-term incubation with organic nitrates. Interestingly, in these experiments ISDN was consistently more potent than GTN in stimulating sGC activity, producing 11 - and 32-fold increases in intracellular cGMP levels at $10^{-4}$ and $10^{-3} \mathrm{M}$, respectively, compared to three- and sevenfold increases at the same concentrations of GTN $(n=4)$. IS-5-N produced only marginal sGC activation with a maximally $2 \cdot 5$-fold increase over basal cGMP levels at $3 \times 10^{-4} \mathrm{~mol} \mathrm{~L}^{-1}(n=3)$. Under the same conditions a portion of the cGMP formed within the endothelial cells was released into the incubation medium. The amounts of cGMP accumulated in the extracellular space also increased with increasing nitrate concentration, but were subject to high interindividual variability. Interestingly, additional $4-27 \%$ of the amounts of cGMP found intracellularly were recovered in the extracellular compartment already $5 \mathrm{~min}$ after addition of the respective organic nitrate (even at the lowest nitrate concentrations applied), indicating significant efflux of cGMP after sGC stimulation in HUVECs (data not shown).

\section{Platelet aggregation}

GTN, ISDN and IS-5-N were all found to be rather poor direct inhibitors of collagen-induced aggregation in human WP with $\mathrm{IC}_{50}$ values of $0.48 \pm 0.07$ and $1.23 \pm 0.26 \mathrm{mmol} \mathrm{L}^{-1}$ for ISDN and IS-5-N, respectively $(n=3)$. No $\mathrm{IC}_{50}$ value was calculated for GTN as the insufficient water solubility of this nitrate precluded construction of a complete concentration-response curve in the absence of organic solvents. Addition of HUVECs to the platelet suspension markedly potentiated organic nitrate-induced platelet inhibition in a cell number-dependent manner $(0.1-$ $8.0 \times 10^{5}$ cells $\mathrm{mL}^{-1}$ ) and also induced partial disaggregation at higher nitrate concentrations (Fig. 5). In 


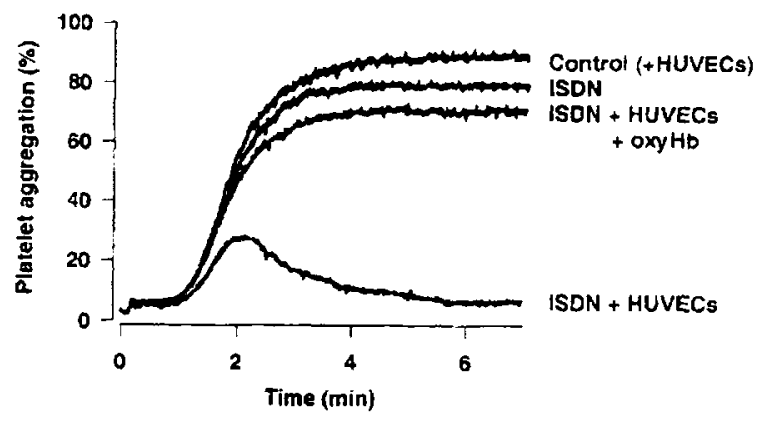

Figure 5. Inhibition of collagen-induced human washed platelet aggregation by ISDN $\left(100 \mu \mathrm{mol} \mathrm{L}^{-1}\right)$ in the absence and presence of cultured HUVECs. Depicted tracings are representative of threefive separate experiments with similar results.

the presence of $4 \times 10^{5}$ endothelial cells $\mathrm{mL}^{-1}$ the $\mathrm{IC}_{20}$ for GTN was shifted to the left by more than two orders of magnitude ( $15 \pm 4 \mu \mathrm{mol} \mathrm{L}^{-1}$ in the absence vs. $0.05 \pm 0.01 \mu \mathrm{mol} \mathrm{L}^{-1}$ in the presence of HUVECs). Addition of endothelial cells alone (up to a maximal number of $4 \times 10^{5}$ cells $\mathrm{mL}^{-1}$ ) had no effect on the control response of platelets to collagen since, for these experiments, HUVECs had been pretreated with both a cyclo-oxygenase (acetylsalicylic acid) and a NO-synthase inhibitor (L-nitroarginine). The potentiating effect of HUVECs on the antiplatelet activity of nitrates was accompanied by a marked (3-10-fold) rise in intraplatelet cGMP levels $(n=3$; data not shown) and appeared to be completely dependent on the generation of NO, as it was abolished upon addition of $10 \mu \mathrm{mol} \mathrm{L}^{-1}$ oxyhaemoglobin (Fig. 5). Pretreatment of HUVECs with NEM resulted in a considerable loss of potentiation of the anti-aggregatory effect of nitrates, whereas the potentiating effect was completely abrogated after preincubation of endothelial cells with glutaraldehyde (Fig. 6).

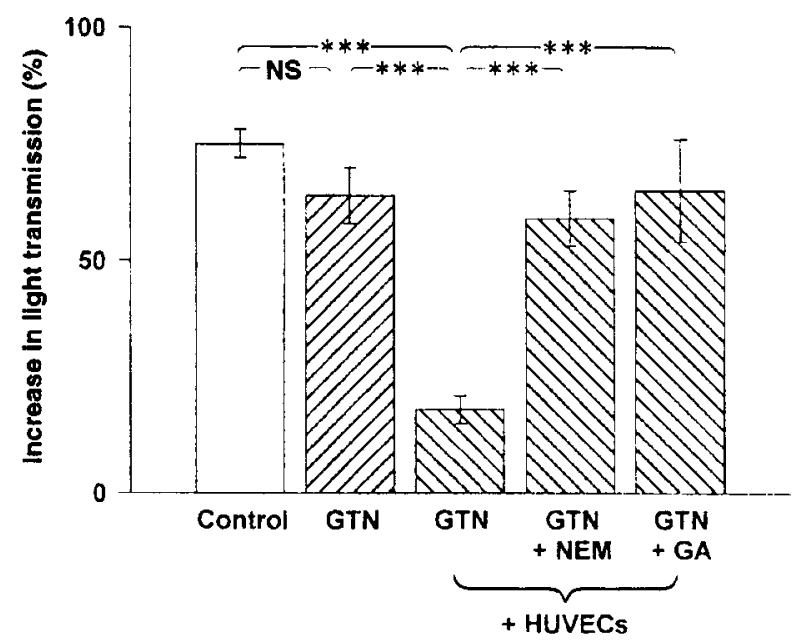

Figure 6. Effect of pretreatment of cultured human endothelial cells with N-ethylmaleimide (NEM) and glutaraldehyde (GA) on the potentiation of GTN-induced anti-aggregatory activity in washed human platelets. For details refer to Methods section. NS $=$ not significant: ${ }^{* * *} P<0.001$.

\section{Discussion}

The major finding of the present study is that human endothelial cells are capable of enzymatically bioactivating organic nitrates to $\mathrm{NO}$ in quantities sufficient to influence endothelial and blood cell function. NO amounts formed during nitrate metabolism in HUVECs were of the same order of magnitude as those produced endogenously. Co-incubation of washed human platelets with human endothelial cells markedly potentiated the anti-aggregatory action of nitrates in a cell number-dependent and oxyhaemoglobin-sensitive manner, thus extending previous observations on the potentiation of antiplatelet activity of organic nitrates by endothelial cells of animal origin $[4,6]$.

As shown earlier for vascular cells of animal origin [5] the profile of NO release arising from the metabolism of GTN in HUVECs was also biphasic. This suggests the involvement of at least two pathways of nitrate bioactivation with a potentially different susceptibility toward down-regulation at higher nitrate concentrations. Interestingly, the profile of $\mathrm{NO}$ release from GTN observed in the present study was remarkably similar to the profile of NO formation detected after application of GTN in the exhaled breath of experimental animals in vivo [17]. Although admittedly speculative, these similarities may indicate the occurrence of a ubiquitous bioconversion pathway for organic nitrates in different vascular cells, irrespective of source and origin. The finding of an increased yield in NO production with decreasing concentrations of the organic nitrate indicates that the metabolizing pathway is saturable at higher substrate concentrations. The ability of HUVECs to metabolize organic nitrates to NO appears to involve interaction with free sulfhydryl groups since the NO forming capacity was largely diminished after pretreatment of cells with the thiol-alkylating agent NEM. The almost complete loss of NO generation from organic nitrates upon pretreatment of HUVECs with the cross-linking agent glutaraldehyde suggests that the majority of this activity is unlikely to result from a non-enzymatic reaction between nitrate ester and membrane-bound SH-groups but is rather enzymatic in nature. The nature of this thiol-sensitive pathway responsible for nitrate bioactivation in endothelial cells remains to be elucidated. It is clear. however, that it is distinct from both the cyclooxygenase and the L-Arg: NO pathway as it persisted in HUVECs pretreated with acetylsalicylic acid and L-nitroarginine, respectively.

Organic nitrate-derived NO formation was accompanied by concentration-dependent and methylene blue-inhibitable increases in intra-endothelial and, upon co-incubation with HUVECs, also intraplatelet cGMP levels. The absolute amounts of cGMP produced upon incubation of HUVECs with organic nitrates in this study were considerably lower compared to the figures obtained with endothelial cells of 
animal origin [5]. Interestingly, even at the lowest nitrate concentrations applied a significant portion of intracellularly formed cyclic GMP was excreted into the extracellular space. This finding extends previous results obtained with isolated aortic tissue [18], which suggested that efflux of cGMP from endothelial cells may neither be the result of a passive diffusion over the cell membrane nor of an overload of cellular regulatory mechanisms, but may rather represent an active cellular process which contributes, together with cyclic nucleotide phosphodiesterases, to the regulation of intracellular cGMP cells. Alternatively, the release of endogenously produced cGMP could theoretically also serve a yet unrecognized messenger function.

Upon repeated short-term application of, or longerterm exposure to, high concentrations of GTN the NO forming pathway in endothelial cells was prone to partial tachyphylaxis, hence confirming and extending previous results obtained with cultured vascular smooth muscle cells and isolated aortic tissue $[5,19,20]$. Taken together, these data suggest that, in addition to neurohumoral counter-regulatory mechanisms in vivo [21] a reduced bioconversion to NO at the level of the vascular cell may contribute, at least in part, to the development of nitrate tolerance. This phenomenon is, however, considered rather irrelevant for the clinical therapy with organic nitrates as it only occurs at pharmacological concentrations which are orders of magnitude higher than therapeutically achieved tissue levels.

Although the results from this in vitro investigation cannot be directly extrapolated to in vivo conditions, one of the advantages of the present investigation is the use of a 'three-dimensional' approach, i.e. the combination of (1) direct chemical detection of NO using a highly sensitive, specific and well characterized technique for its kinetic quantification, the oxyhaemoglobin method; (2) determination of the second messenger response in the generating cell, the endothelium, as well as in a potential target cell, the platelet; and (3) the assessment of functional effects using the measurement of inhibition of human washed platelet aggregation as a bioassay. The use of cultured human endothelial cells rather than human vascular tissue collected post mortem allowed us to clearly separate metabolism in the endothelium from that in the vascular smooth muscle compartment. Monolayer cultures of HUVECs have been chosen as a model to address the question of endothelial nitrate metabolism for the following reasons: they represent a homogenous population of untransformed human cells with an intact L-arginine $\rightarrow \mathrm{NO} \rightarrow$ cGMP pathway, can be conveniently grown in large numbers under clearly defined conditions, and are well characterized with regard to physiological and pharmacological stimulus-response coupling mechanisms. Nevertheless, as generally seen with many other cell types, some enzymatic pathways present in vivo may be impaired when cells are cultured in vitro. Thus, their metabolic profile may differ somewhat from that of native cells under in vivo conditions. However, to our knowledge there is no indication in the literature to suggest that cultured cells may be endowed with new pathways not normally expressed, unless induction processes are triggered. Therefore, the bioactivation pathway described for human endothelial cells in the present investigation is not considered to represent a cell culture phenomenon but, on the contrary, may rather underestimate the true extent of nitrate biotransformation in the endothelium in situ.

As the NO generated from the metabolism of organic nitrates in the vascular endothelium in vivo is not limited to affect the generating cell itself but is also released to both the luminal and the abluminal side, three potential targets for this NO must be considered: (1) the adjacent vascular smooth muscle cell (VSMC); (2) the endothelial cell (EC) itself ; and (3) blood cells coming into close contact with the vascular wall (Fig. 7).

The amount of nitrate-derived NO produced by ECs is likely to be of only minor importance for the overall dilator effect of these drugs, taking into account the total number of ECs as compared to the number of smooth muscle cells in large to mediumsized blood vessels. The contribution of this endothelial pathway of nitrate bioactivation to the modulation of smooth muscle function may, however, be different in smaller blood vessels with different EC/ VSMC ratios. It appears worth investigating whether or not microvascular ECs retain their capacity to metabolize organic nitrates to $\mathrm{NO}$ as this may offer new perspectives for a therapeutic application of these drugs in pathophysiological states which are associated with a disturbed capillary function as, for example, in microvessel disease. The NO derived from the metabolism of organic nitrates in the endothelium may add to the direct inhibitory effect of nitrates on smooth muscle cell mitogenesis and proliferation [22] by specifically inhibiting an increased myocyte proliferation in the subendothelial layer. The nitrate-derived NO may furthermore inhibit the synthesis of collagen [23], a protein exported from vascular smooth muscle cells and important in the genesis of atherosclerotic lesions. Both mechanisms may have contributed to the observed inhibition of neointima formation in an in vivo animal model of atherosclerosis by the new organic nitrate, SPM-5185 [24].

In the endothelium, the NO formed from organic nitrates may modulate, via the second messenger cGMP, the permeability for fluids and macromolecules [25], the expression of adhesion proteins [26], the release of the vasoconstrictor peptide endothelin [27], and endothelial cell proliferation $[28,29]$. It may also contribute, at least in part, to the restoration of endothelial function which is impaired in certain disease states [30]. Interestingly, a specific enhancement of endothelium-dependent vasodilation in patients with endothelial dysfunction has been described recently 


\title{
Vascular smooth muscle
}

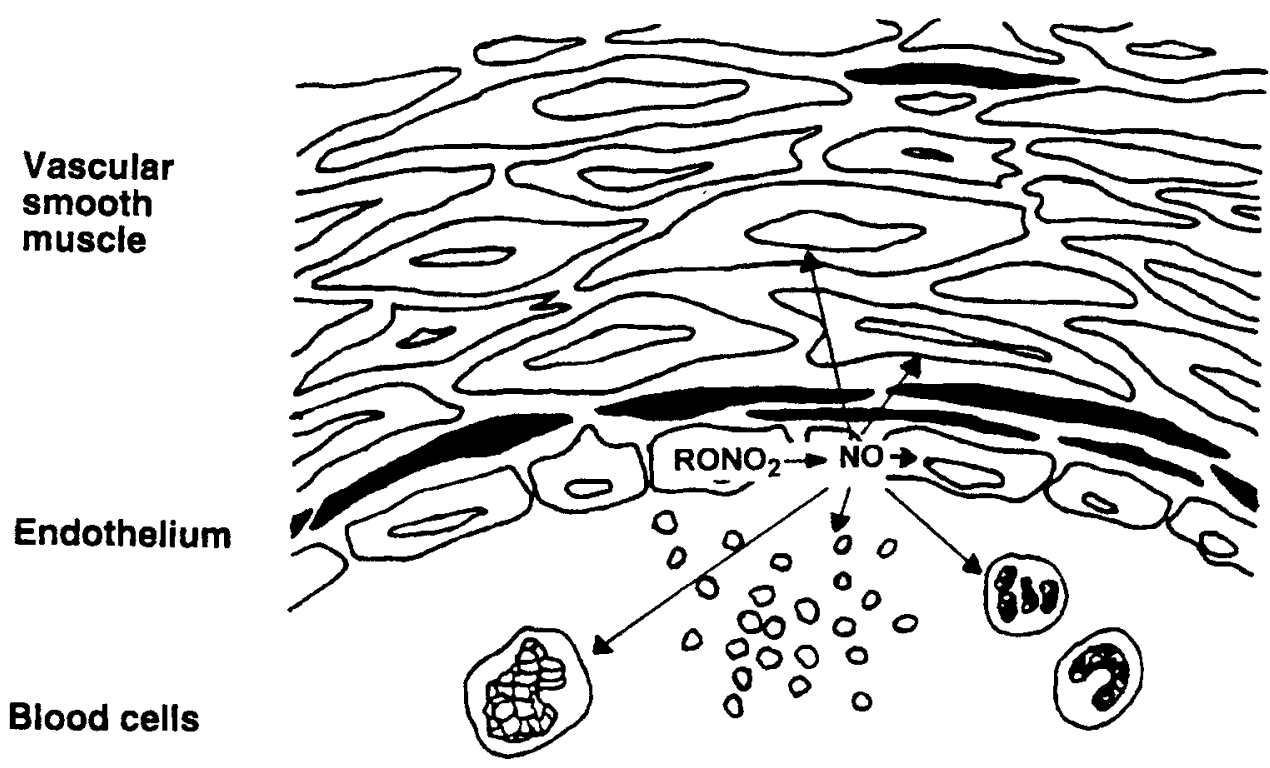

\author{
(Vasorelaxation) \\ Mitogenesis $\downarrow$ \\ Proliferation $\downarrow$ \\ Collagen synthesis $\downarrow$
}

Proliferation $\downarrow \uparrow$

Permeability $\downarrow$

Expr. of adhesion

proteins $\downarrow$

Endothelin release $\downarrow$

Figure 7. Potential interactions of organic nitrate-derived NO from the endothelium on various cellular functions.

following GTN infusion at a dose which did not affect resting forearm blood flow [31]. These data suggest that even under conditions which are associated with an impaired endothelial function nitrates are bioactivated to elicit beneficial effects in the endothelium. It is tempting to speculate that the therapeutic doses of organic nitrates required for modulation of endothelium function may be considerably lower than those in current use for vasorelaxation.

The nitrate-derived NO which is released into the vessel lumen is likely to have an important impact on blood cell/vessel wall interactions by inhibiting the adhesion of platelets [32], neutrophils [26] and monocytes [33], and by inhibiting platelet aggregation [34].

Both the modulation of EC function and adhesiveness as well as blood cell activation are considered key events in thrombus formation and the development of an atherosclerotic lesion [35]. Nitrate bioactivation in the endothelium may offer an attractive explanation for the observed inhibition by ISDN of arterial thrombosis in the rat [36] and may, furthermore, be the sought after key for understanding why the antiplatelet effects of organic nitrates in vivo are generally seen at concentrations which are much lower than those necessary to inhibit platelet aggregation in vitro [37]. An obvious explanation for this discrepancy would be that all classical in vitro assays for evaluation of platelet inhibitory effects lack the presence of metabolically competent cells capable of bioconverting organic nitrates to NO. The endothelium is likely to be the most important cell type for organic nitrate-mediated modulation of blood cell/vessel wall interactions as they are the only vascular cells which come into close contact with blood cells.

Considering the mechanisms discussed above, prodrugs, such as organic nitrates, should be capable of reinforcing endogenous protective functions of the endothelium by additionally supplying NO. Such effects are envisaged to be of particular importance in disease states associated with an impaired LArg: NO pathway [38] where they can partly substitute for the suppressed endogenous NO production. These drugs may thus be endowed with considerable antithrombotic and anti-atherosclerotic activity, adding a new therapeutic dimension to their well known vasorelaxant action. In the light of the above considerations, full appreciation and interpretation of the results of the present study must await future clinical investigations with organic nitrates in disease states beyond the classical indications for these drugs.

\section{Acknowledgments}

We would like to thank Dr V. Küppers from the Department of Obstetrics and Gynaecology, Heinrich-Heine-University, Düsseldorf, for the supply with human umbilical cord, Drs R. Spahr and J. Aissa as well as Mrs G. Alt for expert technical assistance, and Mrs D. Kubitzek for help with the preparation of the manuscript.

\section{References}

1 Murell $\mathrm{W}$. Nitroglycerine as a remedy for angina pectoris. Lancet 1879;1:80-1;113-15;151-2;225-7.

2 Moncada S, Palmer RMJ, Higgs EA. The discovery of nitric oxide as the endogenous nitrovasodilator. Hypertension 1988:12: 365-72.

3 Ignarro LJ. Endothelium-derived nitric oxide: pharmacology and relationship to the actions of organic nitrate esters. Pharm Res 1989;6:651-9.

4 Rolland PH, Berenger PF, Cano JP. In vitro evidence of an endothelial cell-dependent antiplatelet activity for isosorbide dinitrate. but not for its 2- and 5-mononitrate. J Pharmacol Exp Ther 1987;240:234-40.

5 Feelisch M, Kelm M. Biotransformation of organic nitrates to nitric oxide by vascular smooth muscle and endothelial cells. Biochem Biophys Res Commun 1991:180:286-93. 
6 Salvemini D. Mollace V. Pistelli A, Anggard E. Vanc J. Metabolism of glyceryl trinitrate to nitric oxide by endothelial cells and smooth muscle cells and its induction by Escherichia coli lipopolysaccharide. Proc Natl Acad Sci USA 1992:89:9826.

7 Moncadia S. Rees DD. Schulz R. Palmer RMJ. Development and mechanism of a specific supersensitivity to nitrovasodilators after inhibition of vascular nitric oxide synthesis in siro. Proc Natl Acad Sci USA 1991:88:2166-70.

8 Malta E. Biphasic relaxant curves to glyceryl trinitrate in rat aortic rings. Naunyn-Schmiedeberg's A rch Pharmacol 1989:339 $236-43$.

9 Jaffe EA. Nachmann RL. Becker CG. Minick CR. Culture of human endorhelial cells derived from umbilical veins. Identificition by morphologic and immunologic criteria. J Clin Invest 1973:52:2745-56.

10 Voyta JC. Via DP. Butterfield CE. Zetter BR. Identification and isolation of endothelial cells based on their increased uptake of acetylated low-density lipoprotein. J Cell Biol 1984:99:2034-40.

11 Doyle MP. Hoekstra JW. Oxidation of nitrogen oxides by bound dioxygen in hemoproteins. $J$ Inorg Chem 1981:14:351-8.

12 Feelisch M. Noack E. Correlation between nitric oxide formation during degradation of organic nitrates and activation of guanylate cyclase. Eur J Pharmacol 1987:139:19-30.

13 Lowry OH. Rosebrough NJ. Farr AL. Randall RJ. Protein measurement with the folin phenol reagent. J Biol Chem 1951:193:265-75.

14 Kelm M. Schrader J. Control or coronary vascular tone by nitric oxide. Circ Res 1990:66:1561-75.

15 Harper JF. Brooker G. Femtomole sensitive radioimmunoassay for cyclic AMP and cyclic GMP after 2'-O-acetylation by acetic anhydride in aqueous solution. J Cycl Nucl Res 1975:1:207-18.

16 Radomski M. Moncada S. An improved method for washing of human platelets with prostacyclin. Thromb Res 1983:30:383-9.

17 Persson MG. Agvald P. Gustafsson LE. Detection of nitric oxide in exhaled air during administration of nitroglycerin in vivo. Br J Pharmacol 1994:1 11:825-8.

18 Schini V. Schoeffter P. Miller RC. Effect of endothelium on basal and on stimulated accumulation and efflux of cyclic GMP in rat isolated aorta. Br J Pharmacol 1989:97:853-65.

19 Mülsch A. Busse R. Bassenge E. Desensitization of guanylate cyclase in nitrate tolerance does not impair endothelium-dependent responses. Eur J Pharmacol 1988:158:191-8.

20 Slack CJ. McLaughlin BE. Nakatsu K. Marks GS. Brien JF Vitric oxide-induced vasodilation of organic nitrate-tolerant abbit aorta. Can J Physiol Pharmacol 1988:66:1344-6.

21 Fung HL. Bauer JA. Mechanisms of nitrate tolerance. Cardiovasc Drugs Ther 1994:8:489-99.

22 Garg UC. Hassid V. Nitric oxide-generating vasodilators and 8bromo cyclic guanosine monophosphate inhibit mitogenesis and proliferation of cultured rat vascular smooth muscle cells. J Clin Invest $1989: 83: 1774-7$
23 Kolpakov V. Gordon D. Kulik TJ. Nitric oxide-generating compounds inhibit total protein and collagen svnthesis in cultured vascular smooth muscle ceils. Circ Res 1995:76:305-9.

24 deMeyer GRY. Bult H. Üstünes L. Kockx MM. Feelisch M. Herman AG. Effect of SPM-5185, a novel cvsteine-containing nitric oxide donor. on neointima formation and vascular reactivity in the collared carotid artery of the rabbit. J Cardiovasc Pharmacol 1995:26:272-9.

25 Drajer R. Douwe EA. van der Laarse A. van Hinsbergh VWM. CGMP and nitric oxide modulate thrombin-induced endothelial permeabilitv. Regulation via different pathways in human aortic and umbilical vein endothelial cells. Circ Res 1995:76:199-208.

26 Kubes P. Suzuki M. Granger DN. Nitric oxide: An endogenous modulator of leukocyte adhesion. Proc Natl Acad Sei 1991:88: $4651-5$.

27 Boulanger C.M. Lüscher TF. Hirudin and nitrates inhibit the thrombin-induced release of endothelin from the intact porcine aorta. Clin Res 1991:68:1768-72.

28 Moodie SA, Martin W. Effects of cycic nucleotides and phorbol myristate acetate on proliferation of pig aortic endothelial cells Brit J Pharmacol 1991:102:101-6.

29 Yang W. Ando J. Korenga R. Tovo-oka T. Kamiya A. Exogenous nitric oxide inhibits proliferation of cultured vascular endothelial cells. Biochem Biophys Res Commun 1994:203. $1160-7$.

30 Moncada S. Martin JF. Higgs A. Symposium on regression of atheroscierosis. Eur J Clin Invest 1993:23:385-98.

31 Schwarz M. Katz SD. Demopoulos L el al. Enhancement of endothelium-dependent vasodilation by low-dose nitroglycerin in patients with congestive heart failure. Circulation 1994:89. $1609-14$

32 Radomski MW. Palmer RMJ. Moncada S. The role of nitric oxide and CG.MP in platelet adhesion to vascular endothelium. Biochem Biophys Res Commun 1987:1 48:1482-9

33 Tsao PS. McEroy LM. Drexler H. Butcher E. Cooke JP. Enhanced endothelial adhesiveness in hypercholersterolemia is attenuated by L-arginine. Circulation 1994:89:2176-82.

34 Radomski MW. Vallance P. Whitley G. Foxwell N, Moncada S. Platelet adhesion to human vascular endothelium is modulated by constitutive and cytokine induced nitric oxide. Cardiovasc Res 1993:27:1380-2.

35 Alexander RW. Hypertension and the pathogenesis of atherosclerosis. Oxidative stress and the mediation of arterial inflammatory response: a new perspective. Hypertension 1995:25:15561 .

36 Plotkine M. Allix M. Guillou J. Boulou R. Oral administration of isosorbide dinitrate inhibits arterial thrombosis in rats. Eur $\mathrm{J}$ Pharmacol 1991:201:115-16.

37 Stamler JS. Loscalzo J. The antithrombotic effects of organic nitrates. Trends Cardiovasc Med 1991:1:346-53.

38 Moncada S. Higgs EA. The L-arginine-nitric oxide pathway. New Engl J Med 1993:329:2202-12 